\title{
A test of four proposed new dimensions of semantic space
}

\author{
DELOS D. WICKENS and MARC A. LINDBERG \\ The Ohio State University, Columbus, Ohio 43210
}

\begin{abstract}
Four new dimensions of the Osgood semantic space, proposed by Bentler and LaVoie (1972), were tested utilizing the PI release design. The two dimensions of density and reality showed significant release from PI, but the dimensions of familiarity and organization did not. The results were discussed in terms of a second study, which showed measures of dependency of the four new dimensions upon the original three Osgood semantic differential dimensions.
\end{abstract}

Wickens and Clark (1968), using the release from proactive inhibition (PI) technique, found that the original dimensions of Osgood, Suci, and Tannenbaum (1957), evaluative, potency, and activity (EPA), were effective in producing PI release. They concluded, therefore, that the words chosen from the ends of the three dimensions do, in fact, clearly represent different classes of connotative meaning.

Bentler and LaVoie (1972) suggested four additional dimensions to the Osgood et al. (1957) semantic space. These four are density (D), organization $(\mathrm{O})$, reality $(\mathrm{R})$, and familiarity (F) - together called DORF-and are said to be complementary to the already existing dimensions of EPA. In other words, instead of representing a word's connotative meaning by its location in a sphere which has only three orthogonal axes, the authors suggest that four new orthogonal axes should be included, making a word's representation be along seven axes.

In their discussion, Bentler and LaVoie suggest that the question as to whether or not the DORF factors are "general connotative dimensions in the same sense that EPA are remains to be tested" (p. 181). Since the EPA factors are markedly effective in the release from PI paradigm, it seemed that one potential test of the general vigor of the proposed new factors was to investigate their characteristics in the release from PI paradigm (Wickens, 1973).

\section{METHOD}

The subjects were 384 male and female introductory psychology students at The Ohio State University who chose this experiment to meet part of their course requirement. Ninety-six subjects served for each of the four dimensions. The subjects were assigned to groups such that there were $\mathrm{N}$ subjects in each group before the $\mathrm{N}+1$ subject was assigned to a new group.

The words were chosen from Bentler and LaVoie (1972), and were formed into groups of three words, each triad equated for frequency of usage as closely as could be done. Because not enough

This research was supported by the National Science Foundation Grant GB-33680 to the senior author. Reprint requests should be addressed to: Delos Wickens. Department of Psychology. The Ohio State University. 1945 North High Street. Columbus, Ohio 43210. words were provided in the Bentler and LaVoie article for two of the classes, D and F, synonyms were taken from Roget's (1969) thesaurus. The specific words employed for each dimension were: Density-populous, thick, mass, crowded, gang, many, numerous, huddled, constant, continual, plural, majority, vs. infrequent, sparse alone, singular, isolated, few, minority, scarce, thin, scattered, meager, apart. Familiarity-orthodox, routine, typical, replaceable, stereotyped, ordinary, customary, average, example, recurrent, brief, norm, vs. exceptional, unique, rare, unconventional. external, novel, mysterious, exotic, odd, uncommon. difficult. atypical. Orderliness-categorizable, arranged, pattern, symmetrical, predictable, exact, methodological, persistant, steadfast, structured, unmixed, orderly, vs. irregular, variable, rash, haphazard, scattered, vague, unstructured, indecisive, shapeless, disorganized, changeable, uneven. Realityrealizable, truthful, authentic, prevalent, concrete, definite, tangible, usual, plain, undeviating, genuine, sincere, vs. imaginary, fancy, sham, abstract, unreal, false, nonexistent, ghost, fake, impossible, artificial, mock.

The general procedure closely paralleled that of previous PI release experiments. All materials were projected on a wall about $3 \mathrm{~m}$ in front of the subject by a Carousel slide projector, with a Gerbrands tape timer serving to control the time of material presentation.

Following the 2-sec presentation of an asterisk, which served as a signal that a trial was to start, a triad of words was presented. Because the words varied in length as well as in pronounceability. the exposure time of triads varied accordingly. The subjects were instructed beforehand to read the words out loud and as rapidly as they possibly could. Upon commencing the pronunciation of the last word, a number came on, controlled by the experimenter. A three-digit number immediately followed the triads, and the subject counted backwards from it until the recall signal $18 \mathrm{sec}$ later.

The order of appearance of the triads was counterbalanced so that each group of words appeared equally often in each position of the four trials for different subjects. The appropriate control was run after each experimental subject. i.e., the same triad was presented on the critical fourth trial. The shifts were made in both directions.

\section{RESULTS}

Significant PI was found across the first three trials for all groups; density, $F(2,184)=61.56, p<.01$; organization, $F(2,184)=73.178, p<.01$; reality, $\mathrm{F}(2,184)=58.09$; and familiarity, $\mathrm{F}(2,184)=70.30$, $\mathrm{p}<.01$. Two of the proposed dimensions, density $[F(1.92)=7.5, p<.05]$ and reality $[F(1,92)=4.18$, $\mathrm{p}<.05]$ showed significant release from PI on the 
shift trial, while organization $[F(1,92)=.64]$ and familiarity $[\mathrm{F}(1.92)=.120]$ did not.

A method for estimating the amount of release from PI is to calculate the percentage gain of the experimental over the control group on the shift trial. Density and reality showed gains of $26 \%$ and $36 \%$, respectively, while the gains for the nonsignificant dimensions were less than $15 \%$. These gains contrast with those obtained from the EPA dimensions, which approximate $65 \%$.

\section{DISCUSSION}

If the release from PI paradigm can be considered to be one converging operation with regard to comparing the independence and potency of the DORF dimension and the EPA dimension, it must be concluded that these four proposed new dimensions do not stand up very well. Although some effect of the shift trial was found for two of the dimensions, no such effect was found for the other two and neither of the two significant dimensions showed a release effect as great as do any of the EPA dimensions.

In a subsequent experiment, the words of the DORF dimensions were given to groups of subjects, and they were asked to rate them on the EPA dimensions. The polar words of the DORF dimensions - the ones used in the release from PI experimentproduced significantly different EPA ratings. In the instance of the two dimensions, density and reality, which obtained significant release from PI, these polar words differed significantly on all three EPA dimensions. They differed on only two dimensions for familiarity and orderliness. Thus it is possible that the significant shift effect was due in some way to the combined effectiveness of the three EPA dimensions, even though two of these dimensions were not adequate. It should be added that Bentler and LaVoie do not report their dimensions to be completely independent of the Osgood dimensions. There is, therefore, a possibility that the significant release obtained in the two instances resulted from the operation of the three EPA dimensions.

Quite obviously, the results of the present experiments do not invalidate the factor analysis work of Bentler and LaVoie. They do seem to indicate, however, that these new dimensions do not carry the same salience in memory as do the EPA dimensions.

The rating method is usually one which allows the subject a considerable amount of time to analyze each word; and, in addition, the direction that the experimenter gives before the task is begun establishes in the subject a semantically analytical set to guide his future experimental behavior. It is likely to cause him to discover many relationships among his sample of words, which relationships may go unnoticed in the quick give and take of ordinary language usage. It is a bit like the task a literary critic may accept for himself in analyzing some line of poetry as opposed to that taken by the casual reader. Also, when a factor analytic approach is used to analyze the data, the number of dimensions is partially determined by how one arbitrarily defines "independence."

In the Brown-Peterson situation, however, the subject's set is completely different, for he is concerned with encoding the items for the purpose of future recall. The task is a demanding one. He is hurried in the encoding process due to the item's short exposure period, and the immediately presented distractor task gives him little opportunity to review the three target words. He is continuously occupied with the work at hand, save for the few seconds which remain of the recall period before the next trial begins and after he has finished recalling to his own satisfaction. The recall period is only $8 \mathrm{sec}$ in duration, and if the subject does not immediately recall all three items he probably spends much of the time in researching for the unretrieved item or items. The subject, in short, has little time to deal with the nuances of a word, and even though all attributes of a word are encoded-unlikely as this seems to be-he has little time for the process of noting relationships among words of a triad or between the various triads themselves.

Given the difference in the nature of the rating and the release from PI situation, it is not surprising that they result in different answers to the same question. The release from PI method seems to be one which, because of its rapidity, taps only the core structure of the semantic network of the words, whereas the more leisurely rating method gives time for the conscious processing and reprocessing of any of the attributes engendered by the words.

The essential conclusion to be drawn from this research is that the Bentler and LaVoie dimensions do not occupy the same status as do the three SD dimensions. It might be said that although they can be identified as dimensions, they are not basic dimensions in the same sense as are the SD attributes.

\section{REFERENCES}

Bentler, P. M., \& LaVoie, A. L. An extension of semantic space. Journal of Verbal Learning and Verbal Behavior. 1972. 11, 174-182.

Osgood, C. E., Suci, G. J., \& Tannenbaum, P. H. The measurement of meaning. Urbana: University of Illinois Press, 1957.

WICKENS, D. D. Some characteristics of word encoding. Memory \& Cognition, 1973, 1, 485-490.

Wickens, D. D., \& Clark, S. E. Osgood dimensions as an encoding in short-term memory. Journal of Experimental Psychology, 1968, 78, 580-584.

(Received for publication June 19, 1975.) 